\title{
Apresentação
}

\section{A prática científica na "Era do Conhecimento": metodologia e transdisciplinaridade}

MÁRA BAUMGARTEN

\section{Resumo}

0 duplo condicionamento existente entre sociedade e conhecimento científico e tecnológico remete ao lugar estratégico ocupado pelo conhecimento tanto para a economia da sociedade capitalista, quanto para o funcionamento do Estado e para a resolução de questões sociais. Por outro lado, o desenvolvimento científico e tecnológico tem, também, virtualidades negativas que resultam em sérios problemas e crises. As ciências sociais enfrentam hoje o grande desafio de desenvolver conceitos e teorias que sirvam como instrumentos para compreender e intervir sobre processos que têm fortes repercussões sobre a vida cotidiana. A perspectiva da complexidade, com seus diálogos e práticas inter e transdisciplinares parece ser uma boa forma de lidar com as incertezas do mundo contemporâneo que é, sem a menor dúvida, complexo. Apresentamos aqui um pouco do debate acerca do fazer científico atual.

Palavras-chave: Metodologia. Transdisciplinaridade. Prática científica.

\footnotetext{
* Professora do Instituto de Ciências H umanas e da Informação da U niversidade Federal de Rio Grande e do Programa de Pós-graduação em Sociologia da UFRGS. Coordenadora do Laboratório de Divulgação de Ciência, Tecnologia e Inovação Social da U FRGS (www.ufrgs.br/ladcis).
} 


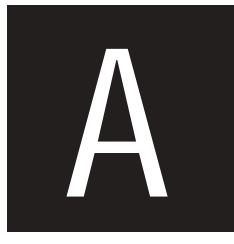

prática científica na sociedade contemporânea é um tema ainda pouco debatido, principalmente quando se leva em conta o lugar da ciência e da tecnologia nos próprios alicerces da sociedade capitalista. 0 duplo condicionamento existente entre sociedade e conhecimento científico remete ao lugar estratégico ocupado pelo conhecimento científico e tecnológico não só para a acumulação capitalista, mas também para o funcionamento do próprio Estado e da sociedade atuais.

Novas possibilidades e desafios de desenvolvimento (como processo de mudança social) emergem das transformações imateriais que se operam tanto na produção material quanto na produção dos intangíveis (M ACIEL, 2001). Em face da emergência de novas formas produtivas e societárias que caracterizam o que alguns denominam "sociedade de informação" e outros chamam "sociedade do conhecimento" ou "do aprendizado" (STEHR, 1994; LASTRES; ALBAGLI, 1999) a produção/distribuição de informação e de conhecimento assume forte centralidade, tanto como instrumento para a análise da sociedade, quanto como objeto de investigação e discussão.

Ao analisar a constituição da ciência moderna e o modelo de fazer científico que se consolidou como hegemônico nos últimos séculos, encontramos um paradigma, assentado na razão, na divisão/análise e na máxima "conhecer para controlar", que reduziu os problemas e suas respostas a modelos para a ação transformadora sobre a natureza e controladora da sociedade, produzindo conhecimentos disciplinares e com alto nível de especialização. Separar e reduzir têm sido as máximas desse paradigma.

Entretanto, como já afirmei em outro momento (BAUMGARTEN, 2006), natureza e sociedade são cada vez mais complexas e o mundo atual é a expressão desta complexidade - os problemas que se nos apresentam são multidimensionais e as contradições se avolumam. 0 ser humano alienado por suas próprias mãos - da natureza (que não deixa por isso de 
integrar), passou a ameaçá-la de forma perigosa para sua própria espécie e todas as outras. O s laços de solidariedade humana se fragilizam, se desfazem e contradições irredutíveis emergem no cotidiano natural e social.

Nesse contexto, as questões que se colocam são: como conhecer e como agir nessa realidade? Como perceber as tantas bifurcações que 0 devir contém, seus feixes de possibilidades? Como escolher caminhos?

A perspectiva da transdisciplinaridade tem sido apontada como alternativa para lidar com as incertezas do mundo contemporâneo, entretanto, se o paradigma da complexidade tem apresentado avanços na perspectiva epistemológica, enquanto aplicação prática tem ainda um longo caminho a percorrer. Por outro lado, as redes de produção, disseminação e apropriação de conhecimentos desempenham hoje um papel central na sociedade, tornando imprescindível a reflexão sobre as mesmas e sobre as repercussões que trazem para as formas de produção e apropriação de conhecimentos, notadamente para as possibilidades do trabalho inter e transdisciplinar.

A proposta desse dossiê é debater algumas dessas questões, buscando iluminar os caminhos atuais do fazer científico e instituir um debate oportuno e necessário sobre o tema.

0 primeiro artigo apresentado é "Interdisciplinaridade e convergência tecnocientífica nano-bio-info-cogno", de Javier Echeverría, pesquisador espanhol que atua no Departamento de Sociología 2, Universidad del País Vasco e é professor de pesquisa do Consejo Superior de Investigaciones Cientificas (CSIC).

Echeverría considera que a emergência da tecnociência no século XX transformou a prática científica e também o conceito de interdisciplinaridade. $\mathrm{O}$ autor analisa um exemplo relevante de tecnociência contemporânea, 0 informe Converging Technologies for Improving Human Performance (CTIHP) da National Science Foundation (NSF) norte americana no qual se promove um novo tipo de interdisciplinaridade, nano-bio-info-cogno (NBIC). Segundo 
Echeverría (2009), a análise do informe da NSF mostra que o conceito de interdisciplinaridade utilizado é instrumental, seletivo e, eventualmente, parece ser reducionista, em prejuízo das ciências sociais, das artes e das humanidades. A partir do debate empreendido, 0 autor sugere que a noção de interprofissionalidade é mais adequada para a tecnociência que a de interdisciplinaridade.

Olivier Giraud - pesquisador do Centro Marc Bloc CNRS (Centre National de la Recherche Scientifique) - no artigo "Comparação dos casos mais contrastantes: método pioneiro central na era da globalização", aborda a meto do logia comparativa centrada nos casos mais contrastantes e mostra a utilidade crescente deste método no mundo atual, marcado pela escalada da globalização. De acordo com Giraud (2009), o método dos casos mais diferentes foi desenvolvido nosanos 1960, época em que se privilegiavam as abordagens estrutural-funcionalistas, que tendiam a mostrar a unicidade ou, pelo menos, a uniformidade das trajetórias de mudança ou de desenvolvimento das sociedades humanas. Esse método demonstrou, em contrapartida, a utilidade de uma ferramenta metodológica que se debruça sobre a pluralidade das formas sociais, tais como as do religioso, do comércio, da conquista, do trabalho, entre outras. Giraud, em seu artigo, busca situar as abordagens comparativas em termos de casos mais diferentes no contexto dos debates meto do lógicos contemporâneos sobre o comparatismo. Em seguida, propõe uma definição da globalização e dos mecanismos que explicam a transformação das condições da comparação em um mundo globalizado (GIRAUD, 2009).

Em “Prática de pesquisa e 'Sociologia pública': uma discussão em torno de cruzamentos possíveis e outros nem tanto", Leonardo M ello (professor e pesquisador da U SP) apresenta uma reação ao chamado For Public Sociology (2005), do sociólogo Michael Burawoy. 0 autor discute as implicações daquele "texto-manifesto" em termos de uma prática de pesquisa 
que incorpora o componente dialógico da proposta e procura mostrar as suas limitações quando faz concessões quer à sociologia profissional, quer à policy sociology.

Tais limitações, de acordo com M ello (2009), são postas à luz tendo por base alguns exemplos extraídos de trabalho de campo próprio, em que o elemento reflexivo da pesquisa impõe uma problematização em termos de relações de poder entrevistador-entrevistado. Mello recorre à abordagem tourainiana da "sociologia da ação" e da "metodologia da intervenção sociológica" para mostrar que a tradição da disciplina já enfrentou o mesmo tipo de questões anteriormente. 0 artigo conclui pela pertinência da "sociologia pública" desde que se levem em conta as incompatibilidades metodológicas com os outros "tipos" de sociologia.

Adrián Scribano e Angélica De Sena (professores da U niversidade de Buenos Aires), no artigo "As segundas partes podem ser melhores: algumas reflexões sobre o uso de dados secundários na investigação qualitativa", tomam como ponto de partida a idéia que a análise de dados secundáriosé uma das estratégias mais antigas que os sociólogos têm empregado para trabalhar com fenômenos da realidade social sobre os quais se dispõe de informação elaborada por outros. O s autores buscam, ao abordar o tema, estabelecer uma reflexão sistemática sobre o uso de informação secundária nosprocessos de investigação social qualitativos. Adrian Scribano e Angélica De Sena (2009) advogam a importância de estabelecer critérios claros que possam facilitar o uso e a análise de informação elaborada por outros e/ou em diferentes contextos de produção.

A professora Tania Steren dos Santos, do D epartamento de Sociologia da UFRGS e co-organizadora do dossiê, apresenta o artigo “Do artesanato intelectual ao contexto virtual: ferramentas metodológicas para a pesquisa social". Diversos procedimentos metodológicos são abordados, considerando especialmente as técnicas de pesquisa, tanto as mais tradicionais, como 
as novas estratégias utilizadas na pesquisa social no contexto da sociedade da informação. A autora salienta o impacto da incorporação das novas tecnologias da informação e da comunicação na pesquisa bibliográfica e documental e na pesquisa de campo e questiona a dicotomia das abordagens quantitativas e qualitativas, considerando sua complementaridade e interfaces (STEREN DOSSANTOS, 2009).

A partir do conjunto heterogêneo e denso de questões apresentadas pelos diversos artigos espera-se contribuir para iluminar o debate sobre 0 fazer científico atual, tendo como guia a idéia que as ciências sociais enfrentam hoje o grande desafio de desenvolver conceitos e teorias que sirvam como instrumentos para compreender e intervir sobre processos que têm fortes repercussões sobre a vida cotidiana.

O debate acerca dasformas de produzir conhecimentossobre natureza e sociedade - avanços, problemas, métodos e técnicas - e a discussão sobre a perspectiva da complexidade, com seus diálogos e práticas inter e transdisciplinares podem, talvez, auxiliar a coletividade científica a lidar com asincertezas do mundo contemporâneo e possibilitar a necessária reflexividade na construção de conhecimentos sobre um mundo cada vez mais complexo.

\section{The scientific practice in the "Age of Knowledge": methodology and transdisciplinarity}

\section{Abstract}

The double conditioning between the society and the scientific and technological knowledge refers to the strategic place of knowledge in the economy of capitalist society, as well as in the functioning of the state and the resolution of social issues. On the other hand, the scientific and technological development has also negative aspects that result in serious problems and crises. The social sciences currently face the challenge of developing concepts and theories to serve as tools 
to understand and act on processes that have a strong impact on everyday life. The perspective of complexity, with its dialogues and inter- and transdisciplinary practices, seems like a good way to deal with the uncertainties of the contemporary world, which is certainly complex. This paper presents part of the debate on current scientific practice.

Keywords: Methodology. Transdisciplinarity. Scientific practice.

\section{Referências}

BAU M GARTEN, M. Complexidade e conhecimento: ordem, caos e complexidade. In: Sociologias, ano 8, n. 15 janeiro/junho de 2006, p 16 a 23. Porto Alegre: PPGS.

BURAW OY, M. For public Sociology, American sociological review, v.70, february 2005, p. 4-28. [Tradução em língua portuguesa: Por uma Sociologia pública. Política \& Trabalho. Revista de Ciências Sociais. n.25, out. 2006. p. 9-50.

ECHEVERRÍA, J. Interdisciplinariedad y convergencia tecnocientífica nano-bioinfo-cogno In: Sociologias, ano 11, n. 22 julho/dezembro de 2009.

GIRAU D, O . Comparação dos casos mais contrastantes: método pioneiro central na era da globalização. In: Sociologias, ano 11, n. 22 julho/dezembro de 2009. M ELLO, L. Prática de pesquisa e "Sociologia pública": uma discussão em torno de cruzamentos possíveis e outros nem tanto. In: Sociologias, ano 11, n. 22 julho/ dezembro de 2009.

STEREN DOSSANTOS, T. Do artesanato intelectual ao contexto virtual: ferramentas metodológicas para a pesquisa social. In: Sociologias, ano 11, n. 22 julho/ dezembro de 2009.

SCRIBANO , A.; DE SENA, A. Las segundas partes sí pueden ser mejores: algunas reflexiones sobre el uso de datos secundarios en la investigación cualitativa. In: Sociologias, ano 11, n. 22 julho/dezembro de 2009. 